\title{
Reseña sobre el "Grupo Archivo de Música”, GAMUS, en su décimo aniversario 2009-2019
}

El Grupo Archivo de Música, GAMUS, nació en 2009, a partir de la iniciativa de un conjunto de personas amantes de la música, comprometidas con el patrimonio musical -su rescate, recuperación, conservación, difusión y proyección social-. Desde su origen esta agrupación ha estado integrada por personas vinculadas al Archivo de Música de la Biblioteca Nacional, coordinado por el compositor Gabriel Matthey Correa, quien participa en representación de la Asociación Nacional de Compositores-Chile, ANC. Si bien en un comienzo cada persona se acercaba espontáneamente al Archivo, gracias a la coincidencia de intereses y motivaciones -incluida la vocación pública-, ello naturalmente se tradujo en la creación del GAMUS, con el propósito de trabajar en forma organizada y persistente, para así poder ofrecer un mejor apoyo y colaboración al Archivo de Música de la Biblioteca Nacional.

Así, por tanto, esta agrupación se constituyó como un equipo voluntario, que hasta hoy trabaja en forma regular y sistemática en el fomento de la música chilena, cuyo principal objetivo es contribuir a la gestión de contenidos y redes de apoyo al servicio del Archivo de Música. Para ello colabora en distintas acciones, como la donación de partituras y documentos de compositores/as, charlas, conciertos, entrevistas, talleres, mesas redondas, exhibición de videos o películas documentales y presentación de libros, todo relacionado con nuestra vida musical. Estas actividades se realizan preferentemente en la sala del mismo Archivo, aunque a veces también en la Sala Alonso de Ercilla o en la Sala América de la Biblioteca Nacional, cuando la ocasión lo amerita. Frente a este quehacer, para poder trabajar con sentido y en forma organizada, el GAMUS se reúne mensualmente con la Jefa del Archivo, colaborando cada año en la planificación de las actividades.

Perseverando en esta dinámica, en 2019 la agrupación cumplió diez años de vida, pudiéndose distinguir dos etapas principales en su trayectoria. La primera -período 2009-2012-, cuando el Jefe del Archivo de Música era Mauricio Castro, período en que participaron activamente Fernanda Ortega (pianista y musicóloga, cofundadora del GAMUS), Guadalupe Becker (licenciada en letras hispánicas y musicóloga) y Álvaro Gallegos (periodista especialista en música), entre otras personas. En la segunda etapa, a partir del mismo año 2012, la Jefa del Archivo pasó a ser Cecilia Astudillo, con quien el GAMUS coordina su trabajo hasta la fecha. Desde entonces, algunos integrantes han continuado participando y otros se han ido renovando, tal cual es la tónica habitual de nuestra agrupación, que siempre está atenta a adaptarse a los cambios en función de un mejor servicio a la música chilena, para así poder mantenerse actualizada y vigente.

Siguiendo adelante, si bien en un principio el Archivo centraba sus actividades principalmente en la música de tradición escrita, poco a poco su campo de acción se fue ampliando hacia diferentes géneros musicales, lo que también significó ampliar la configuración del GAMUS. De esta manera, al momento de cumplir diez años de vida, dentro de sus principales participantes -como representantes de distintos ámbitos musicales- se puede mencionar a Nicolás Cortés y Gabriel Matthey (Asociación Nacional de Compositores, ANC), Jorge Mahú (Sociedad Chilena del Derecho de Autor, SCD), Soledad Minio (música folclórica), Dominique Thomann (Teatro Municipal), Cecilia Reyes (Centro de Extensión Artística y Cultural, U. de Chile), Marisol García (periodista, editora de música 
popular.cl), Italia Neira (Industria Musical Independiente, IMI-Chile), Nicolás Araya (Grupo de Estudios Interdisciplinarios de Registros Históricos, EIRH) y Francisco Miranda (Archivos digitales, Departamento de Sonido de la Facultad de Artes, Universidad de Chile). Además, en los últimos años también se fueron incorporando varios jóvenes independientes, de diferentes profesiones quienes realizaron su práctica profesional y/o pasantía en el Archivo de Música-, como son Jorge Canales, Bárbara Chamorro, Ana María Díaz, Nicolás Galindo, Dania Sánchez y Yasna Valenzuela, entre otros. Y en su momento igualmente participaron David Cortés (ANC-Chile), Pamela Olmedo (Asociación Latinoamericana de Profesores de Piano, ALAPP) y Germán Torres (IMI-Chile).

En términos concretos, como parte de las acciones del GAMUS, en el ámbito de la tradición escrita se ha gestionado la donación de partituras y documentos de destacados compositores y compositoras chilenos, como Miguel Aguilar (Concepción); Leni Alexander, Miguel Letelier, Sylvia y Gastón Soublette, Ariel Vicuña y Cirilo Vila (Santiago); y Hernán Ramírez (Viña del Mar), entre otros. En relación con la música popular o folclórica, se han gestionado donaciones del grupo Congreso, Valentín Trujillo, Calatambo Albarracín y Eduardo Peralta, dentro de una lista que siempre va en aumento.

No obstante, el GAMUS constantemente está generando nuevas iniciativas, en pro de fortalecer y cumplir con su misión musical. Por este motivo, en el contexto de su décimo aniversario creó un "Reconocimiento al mérito", el que se entrega a quienes hayan realizado un aporte significativo a la música chilena, a condición (por bases) de que nunca antes hayan sido reconocidos públicamente. Las personas elegidas para su primera versión, el mismo año 2019, fueron Nancy Sattler (Santiago) y Francisco Duarte (Putaendo).

Finalmente, valga renovar aquí el compromiso con el Archivo de Música de la Biblioteca Nacional, que cuenta con el apoyo y colaboración permanente del GAMUS. Nuestro trabajo es siempre voluntario, dentro de un proceso dinámico y participativo, en constante actualización y desarrollo, donde es la música chilena la que está en primer lugar, debidamente protegida y difundida -en forma inclusiva y democrática-, abierta a toda la comunidad nacional e internacional.

Gabriel Matthey Correa Coordinador del GAMUS

Facultad de Artes, Universidad de Chile, Chile gmattheyc@hotmail.com 